\title{
Improvement Solutions and Methodology of UAV Micro-class Aerodynamic Characteristics
}

\author{
Aleksandrs Urbahs ${ }^{1}$, Vladimirs Petrovs ${ }^{2}$, Margarita Urbaha ${ }^{3}$, Kristine Carjova $^{4}$ \\ ${ }^{1-4}$ Institute of Aeronautics, Faculty of Transport an Mechanical Engineering, Riga Technical University
}

\begin{abstract}
The paper contains the analysis of basic features characterizing the development and modernization of micro-class unmanned aerial vehicle (UAV) performance characteristics. The UAV is mainly used for environmental monitoring and for the monitoring of different industrial facilities. The study offers the ways of modernizing the UAV embodiment. It considers the methodology for improving UAV aerodynamic and structural characteristics by using modern calculation methods. The study also includes a theoretical investigation and computer simulation of aerodynamic characteristics.
\end{abstract}

Keywords - Aerodynamics, calculation, modernization, unmanned aerial system.

\section{INTRODUCTION}

The design of an unmanned aerial vehicle (UAV) [1] should take into consideration a number of specific requirements, including the requirement for providing a flexible manufacturing technology, reliable and safe operation, environmental safety, etc. The first of the above-mentioned factors implies the possibility of mass, easy to re-equip production of multi-purpose UAVs differing by their embodiment, mass, arrangement, and functions to be performed. In this case, the design must consist of separate modules made as interchangeable parts and units. Separate parts should be manufactured by using cutting edge technologies and machining facilities.

The UAV developed at the Institute of Aeronautics of Riga Technical University complies with the above requirements. The created UAV system has been successfully applied to perform different tasks in accordance with its specification and has shown high operational efficiency [2], [3]. The system has completely confirmed in practice the underlying technical and operating characteristics [3]. However, the performance of some operations required a vehicle of the same class with better performance characteristics. Design and manufacturing of a prototype model of the given UAV type with improved characteristics need time, resources and other expenses; therefore, an attempt was made to carry out modernization on the basis of the existing prototype to obtain improved characteristics such as flight time, permissible takeoff weight, improved characteristics of using disposable load.

\section{The ANALYSiS OF ACtUAl UAV Characteristics AND MODERNIZATION CHARACTERISTICS}

The developed UAV is based on a classical design with an electric thrust motor. The original UAV design is provided with special compartment for carrying disposable load (Fig. 1).

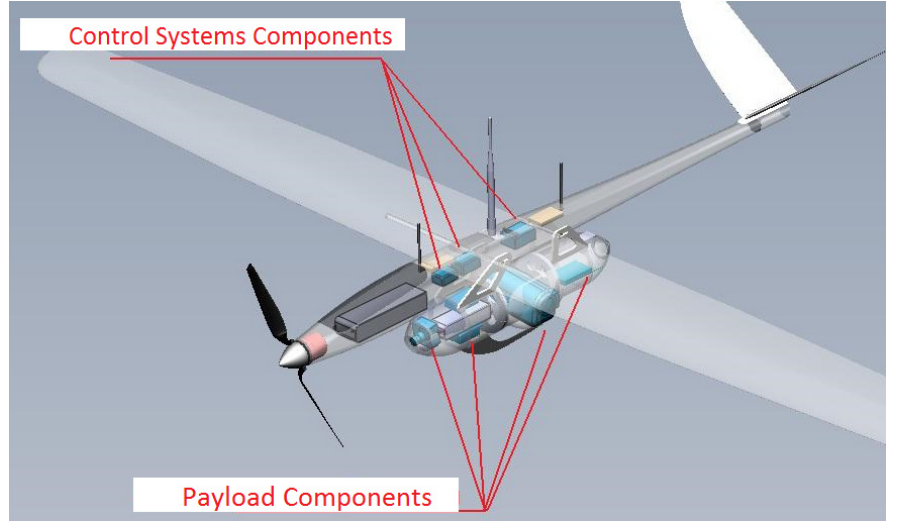

Fig. 1. Layout drawing of UAV.

The designed UAV is characterized by the following key features:

- maximum takeoff weight $-2.5 \mathrm{~kg}$;

- flight duration - up to 1 hour;

- flight altitude - up to $3 \mathrm{~km}$;

- useful load - up to $1.5 \mathrm{~kg}$;

- engine type - electric.

The UAV design includes different innovative materials such as combination of polystyrene materials, composite materials on the basis of carboxylic and Kevlar fabric. The main bearing structures of the UAV are made of extra strong carboxylic tubular members. The centre section has partially stressed skin, which makes it possible to enhance the UAV structural strength and stiffness in general as well as reducing the weight of basic load-bearing elements.

The UAV is able to carry out environmental monitoring, define the location of different object and targets with high accuracy, map seats of fire and areas of environmental pollution. One of the substantial drawbacks of the system is a limited angle of surveillance camera rotation - the camera can turn within the range "down - sideways - to the left" in the direction of flight without covering the right field of view [4]. For the modernization of the system, the following characteristics were taken:

- maximum takeoff weight $-2.7 \mathrm{~kg}$;

- flight duration - up to 1.5 hours;

- flight altitude - up to $3 \mathrm{~km}$;

- useful load - up to $1.5 \mathrm{~kg}$;

- engine type - electric;

- angle of camera rotation $-180^{\circ}$. 


\section{The Analysis of Possible Methods For MODERNIZING THE UAV PROTOTYPE}

As it can be seen, the main objectives of modernization are flight duration, which can be achieved either by reducing the UAV takeoff weight or by installing a power battery of increased capacity. The first variant is unacceptable because the existing prototype already has a design with the weight that is optimized to the maximum, and the takeoff weight can be reduced only by adding disposable load with worse characteristics. The most acceptable variant is the one with an improved power plant that includes a power battery of increased capacity and a more powerful motor. Another method of improving the characteristics of the power unit is increasing the engine operating voltage, which leads to the increase in propeller revolutions. However, this variant will inevitably result in the increase in UAV prototype takeoff weight at least by $0.2 \mathrm{~kg}$. Consequently, it is necessary to reconsider the aerodynamic characteristics of planes and choose the optimal design.

\section{CAlculation And Analysis of Plane AERODYNAMICS FOR UAV MODERNIZATION}

The calculation was performed for a wing with MH32 aerofoil (in calculations, wing " $W 1$ ") and for a new wing with new geometry and SD7032 aerofoil (in calculations, wing "W 2”). Wing $W 1$ is already applied to UAV R 4 (Fig. 2, Fig. 3), and the purpose of this calculation is to reveal the best geometry and aerofoil for the new wing.

Key features of aerial vehicle R 4 used for the calculation:

- maximum takeoff weight - $1550 \mathrm{~g}$;

- cruising speed - $55 \mathrm{~km} / \mathrm{h}$;

- fuselage length - $1178 \mathrm{~mm}$;

- fin area $-1.80 \mathrm{dm}^{2}$;

- stabilizer area $-5.81 \mathrm{dm}^{2}$.

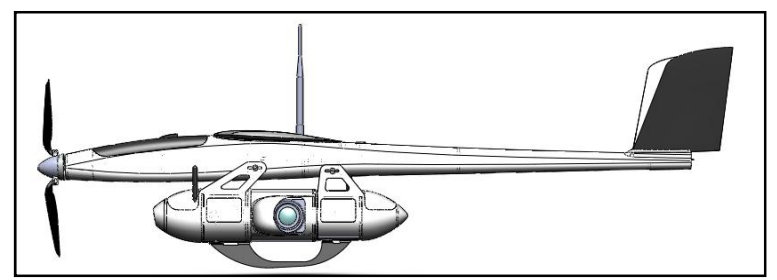

Fig. 2. UAV - side view.

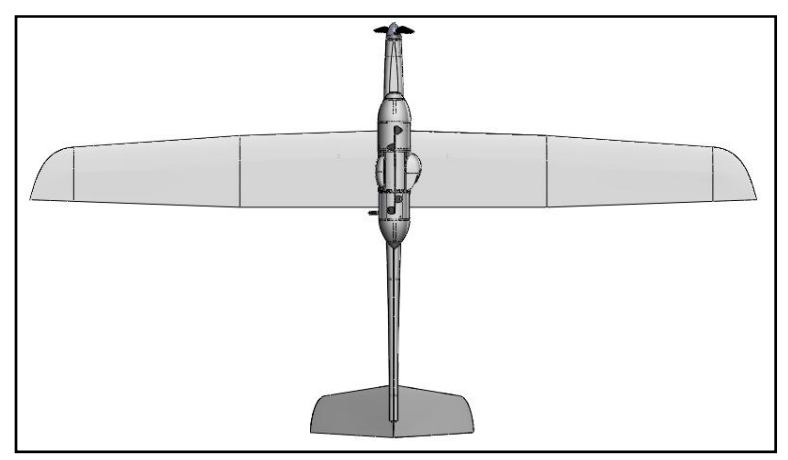

Fig. 3. UAV - bottom view.

\section{A. Aerofoil Analysis}

Wing W 1 has aerofoil MH32 (Table I), and in the process of operating UAV R 4 the following features of UAV have been revealed:

- the UAV has increased landing speeds, which hinders landing on a limited area without maneuvering for speeddown.

- the UAV has "sharp" stall speed boundary.

- the UAV has unstable behavior at a design cruising speed $(55 \mathrm{~km} / \mathrm{h})$; in the process of operating it has been revealed that the most favorable airspeed for target monitoring is $60-65 \mathrm{~km} / \mathrm{h}$.

- the UAV requires pitch trim when the engine power values range from average to maximum.

During the statistical analysis, aerofoil SD7032 (Table II) was used for the new wing.

For the initial calculation a comparative analysis of the polar curve of aerofoils MH323 and SD7032 was carried out; the calculation was made using value $R e=270$ 000, which corresponds to the aerofoil chord of $220 \mathrm{~mm}$, flight speed of $65 \mathrm{~km} / \mathrm{h}$ and flight altitude of $100 \mathrm{~m}[5,6]$.

TABLE I

CAlCulation For AEROFOIL MH32 (FOR ANGLE $A$ )

\begin{tabular}{|r|l|l|l|l|}
\hline \multicolumn{1}{|c|}{$\mathrm{MH} 32-\mathrm{Re}=270000$} \\
\hline Alfa & $\mathrm{Cl}$ & $\mathrm{Cd}$ & $\mathrm{Cl} / \mathrm{Cd}$ & $\mathrm{Cm}$ \\
\hline 0.0 & 0.3352 & 0.0076 & 44.1053 & -0.0722 \\
\hline 0.5 & 0.3782 & 0.0075 & 50.4267 & -0.0691 \\
\hline 1.0 & 0.4238 & 0.0075 & 56.5067 & -0.0665 \\
\hline 1.5 & 0.4710 & 0.0075 & 62.8000 & -0.0643 \\
\hline 2.0 & 0.5196 & 0.0076 & 68.3684 & -0.0623 \\
\hline 2.5 & 0.5689 & 0.0078 & 72.9359 & -0.0606 \\
\hline 3.0 & 0.6179 & 0.0081 & 76.2840 & -0.0589 \\
\hline 3.5 & 0.6669 & 0.0086 & 77.5465 & -0.0573 \\
\hline 4.0 & 0.7156 & 0.0090 & 79.5111 & -0.0559 \\
\hline 4.5 & 0.7637 & 0.0096 & 79.5521 & -0.0544 \\
\hline
\end{tabular}

TABLE II

CAlculation For AEROFOIL SD7032 (FOR ANGLE $A$ )

\begin{tabular}{|r|l|l|l|l|}
\hline \multicolumn{6}{|l|}{$\mathrm{SD} 7032-\mathrm{Re}=270000$} \\
\hline Alfa & $\mathrm{Cl}$ & $\mathrm{Cd}$ & $\mathrm{Cl} / \mathrm{Cd}$ & \multicolumn{1}{l|}{$\mathrm{Cm}$} \\
\hline 0.0 & 0.4424 & 0.0078 & 56.7179 & -0.0917 \\
\hline 0.5 & 0.4990 & 0.0078 & 63.9744 & -0.0916 \\
\hline 1.0 & 0.5552 & 0.0080 & 69.4000 & -0.0913 \\
\hline 1.5 & 0.6108 & 0.0082 & 74.4878 & -0.0911 \\
\hline 2.0 & 0.6659 & 0.0084 & 79.2738 & -0.0907 \\
\hline 2.5 & 0.7206 & 0.0088 & 81.8864 & -0.0904 \\
\hline 3.0 & 0.7748 & 0.0092 & 84.2174 & -0.0900 \\
\hline 3.5 & 0.8287 & 0.0096 & 86.3229 & -0.0896 \\
\hline 4.0 & 0.8818 & 0.0101 & 87.3069 & -0.0892 \\
\hline 4.5 & 0.9327 & 0.0108 & 86.3611 & -0.0885 \\
\hline
\end{tabular}

From the comparative analysis (Fig. 4, Fig. 5) it follows that: for aerofoil MH32 when $\alpha=0^{\circ}$, value $C l=0.3352$; $C d=$ 0.0076; $\mathrm{Cl} / \mathrm{Cd}=44$; 
for aerofoil SD7032 when $\alpha=0^{\circ}$, value $C l=0.4424$; $C d=$ $0.0078 ; \mathrm{Cl} / \mathrm{Cd}=56$.

The lift-drag ratio of aerofoil SD7032 is higher for value $\alpha$ from $0^{\circ}$ to $+4.5^{\circ}$.

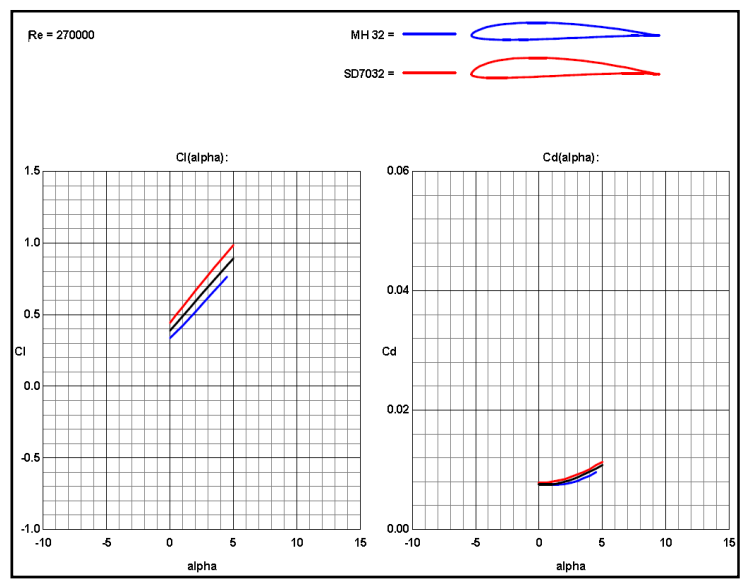

Fig. 4. The comparative diagram of polar curves for $C l$ from angle $\alpha$ and $C d$ from angle $\alpha$.

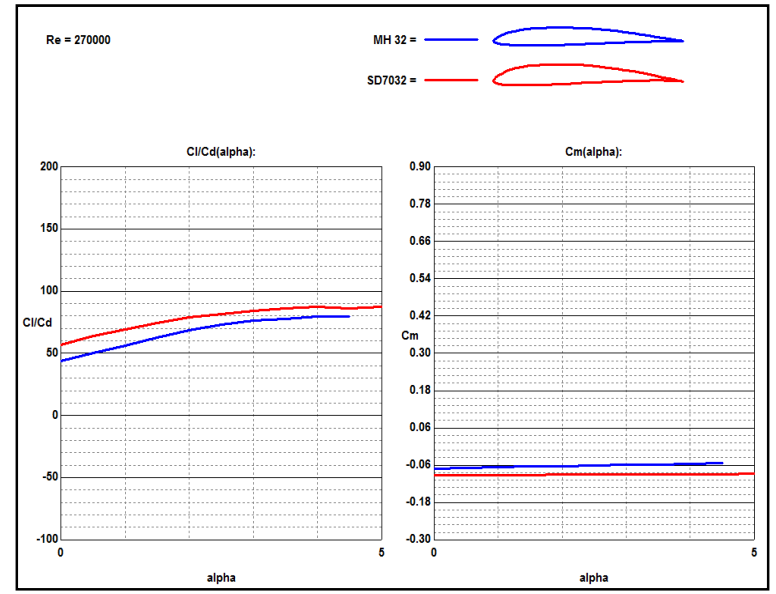

Fig. 5. The comparative diagram of polar curves for $\mathrm{Cl} / \mathrm{Cd}$ from angle $\alpha$ and Cm from angle $\alpha=0^{\circ}$.

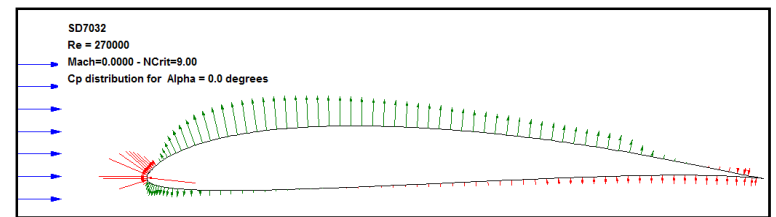

Fig. 6. Pressure distribution over the surface of aerofoil SD7032 when $\alpha=0^{\circ}$.

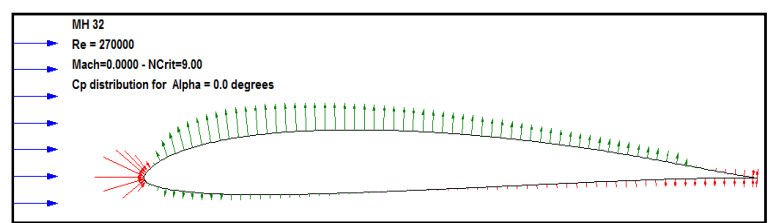

Fig. 7. Pressure distribution over the surface of aerofoil MH32 when $\alpha=0^{\circ}$.
From the analysis of the aerofoils (Fig. 6, Fig. 7) it follows that aerofoil SD7032 is more advantageous in terms of a liftdrag ratio when the set-up parameters are applied [7].

B. Analysis of the $U A V$ with $W 1$

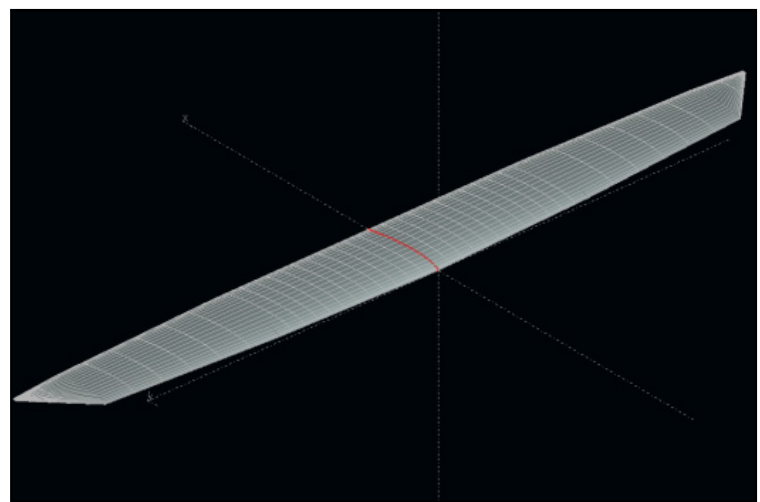

Fig. 8. Plan of wing $W 1$.

Characteristics of wing $W 1$ (Fig. 8):

- maximum span - $2010 \mathrm{~mm}$;

- root chord - $220 \mathrm{~mm}$;

- wing load $-72.524 \mathrm{~g} / \mathrm{dm}^{2}$;

- $\mathrm{MGC}-181.10 \mathrm{~mm}$;

- MAC - $192.17 \mathrm{~mm}$;

- wing area $-36.40 \mathrm{~g} / \mathrm{dm}^{2}$.

The calculation was made for an UAV model with the following characteristics (Fig. 9):

- maximum takeoff weight - $1550 \mathrm{~g}$;

- cruising speed $-55 \mathrm{~km} / \mathrm{h}$;

- fuselage length - $1178 \mathrm{~mm}$;

- fin area $-1.80 \mathrm{dm}^{2}$;

- stabilizer area $-5.81 \mathrm{dm}^{2}$.

UAV stabilizer has a conventional design; the calculation does not take into consideration the nacelle geometry.
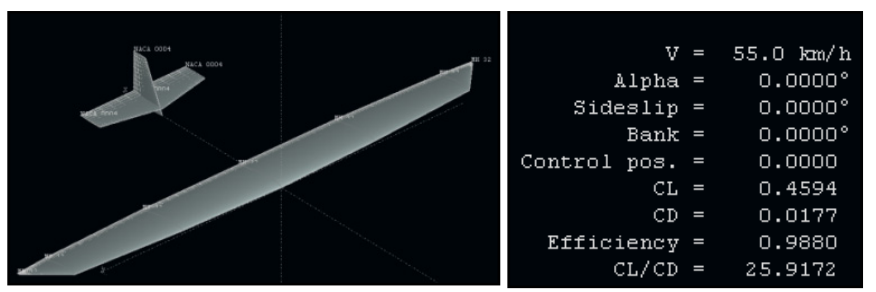

Fig. 9. UAV geometry for calculating wing $W 1$.

The initial calculation was made to reveal the general polar curve of the UAV and aerodynamic characteristics at airspeed $V=55 \mathrm{~km} / \mathrm{h}$ (a design cruising speed) (Fig. 10, Fig. 11) [8].

When $V=55 \mathrm{~km} / \mathrm{h}$, the lift-drag ratio is $C l / C d=25 ; C l=$ $0.4594 ; C d=0.0177$.

A secondary calculation was carried out to reveal the general polar curve of the UAV when the wing lift was constant. 
$2014 / 1$

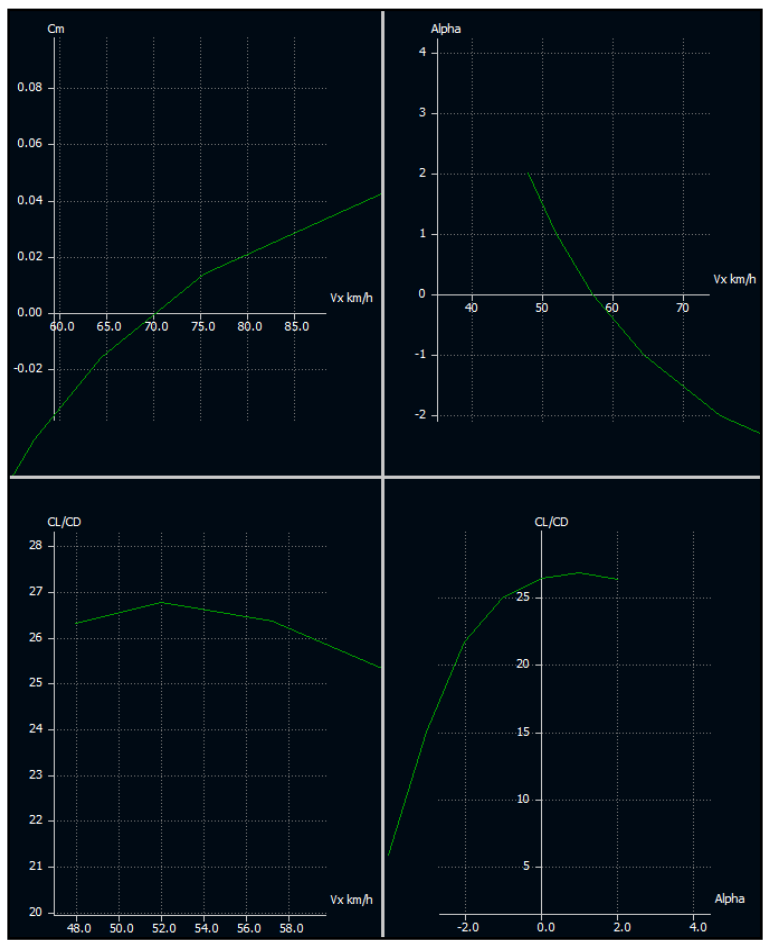

Fig. 10. Diagrams of the polar curve for UAV with wing $W 1$.

From the calculation it is seen that the moment of UAV stabilization $C m=0$ takes place at a speed $V=70 \mathrm{~km} / \mathrm{h}$; the angle of UAV attack becomes $\alpha=0^{\circ}$ at a speed $V=58 \mathrm{~km} / \mathrm{h}$; maximum lift-drag ratio $\mathrm{Cl} / \mathrm{Cd}$ is reached at a speed $V=52$ $\mathrm{km} / \mathrm{h}$; maximum lift-drag ratio $\mathrm{Cl} / \mathrm{Cd}$ occurs when $\alpha=1.5^{\circ}$ [9], [10].

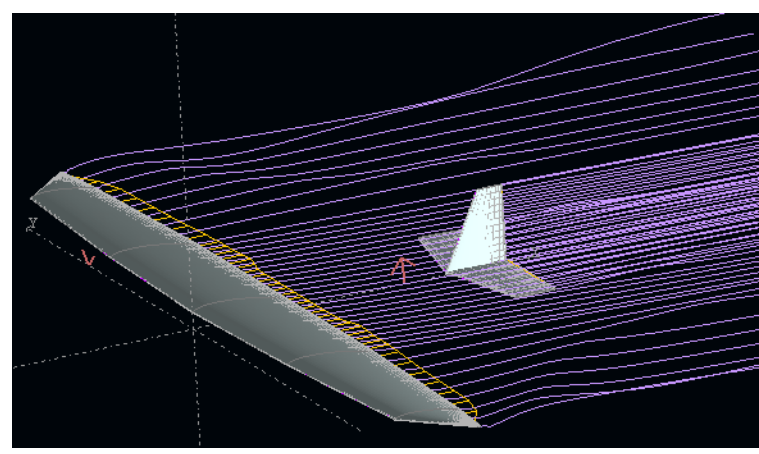

Fig. 11. Picture of flow over wing $W 1$ at the airspeed of $55 \mathrm{~km} / \mathrm{h}$.

\section{Analysis of the UAV with Wing $W 2$}

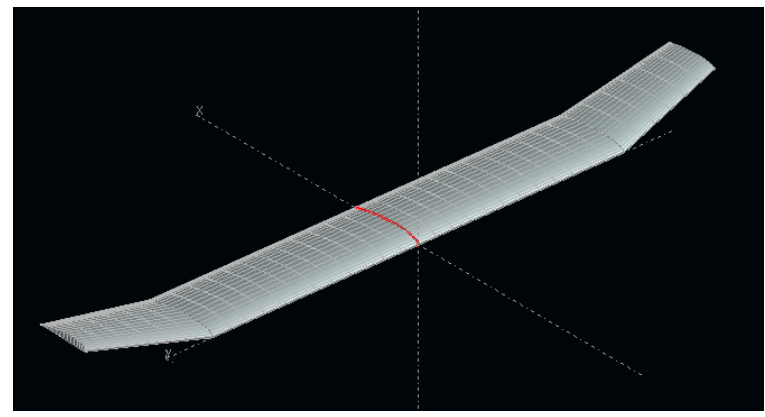

Fig. 12. Plan of wing $W 2$.
Characteristics of wing $W 2$ (Fig. 12):

- maximum span - $2000 \mathrm{~mm}$;

- root chord - $230 \mathrm{~mm}$;

- wing load $-60.730 \mathrm{~g} / \mathrm{dm}^{2}$;

- $\mathrm{MGC}-218.63 \mathrm{~mm}$;

- $\mathrm{MAC}-220.29 \mathrm{~mm}$;

- wing area $-43.73 \mathrm{dm}^{2}$.

The calculation was made for an UAV model with the following characteristics (Fig.13, Fig.14):

- maximum takeoff weight - $1750 \mathrm{~g}$;

- cruising speed - $55 \mathrm{~km} / \mathrm{h}$;

- stabilizer area $-5.81 \mathrm{dm}^{2}$;

- fuselage length - $1178 \mathrm{~mm}$;

- fin area $-1.80 \mathrm{dm}^{2}$.

UAV stabilizer has a conventional design; the calculation does not take into consideration the nacelle geometry.

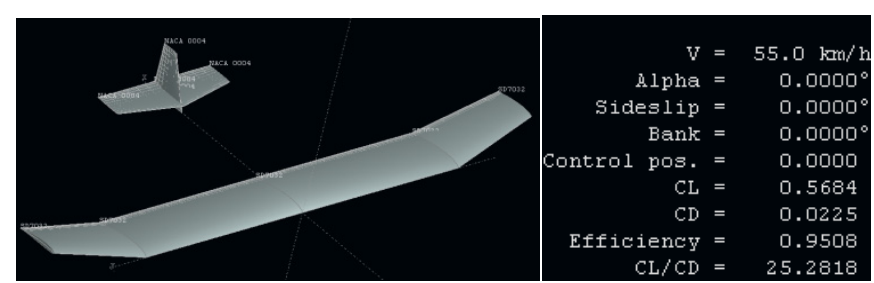

Fig. 13. UAV geometry for calculating wing $W 2$.

The initial calculation was made to reveal the general polar curve of the UAV and aerodynamic characteristics at airspeed $V=55 \mathrm{~km} / \mathrm{h}$ (a design cruising speed) [1].

A secondary calculation was carried out to reveal the general polar curve of the UAV when the wing lift was constant [11].

Diagrams of the polar curve for UAV with wing $W 2$ are shown below.

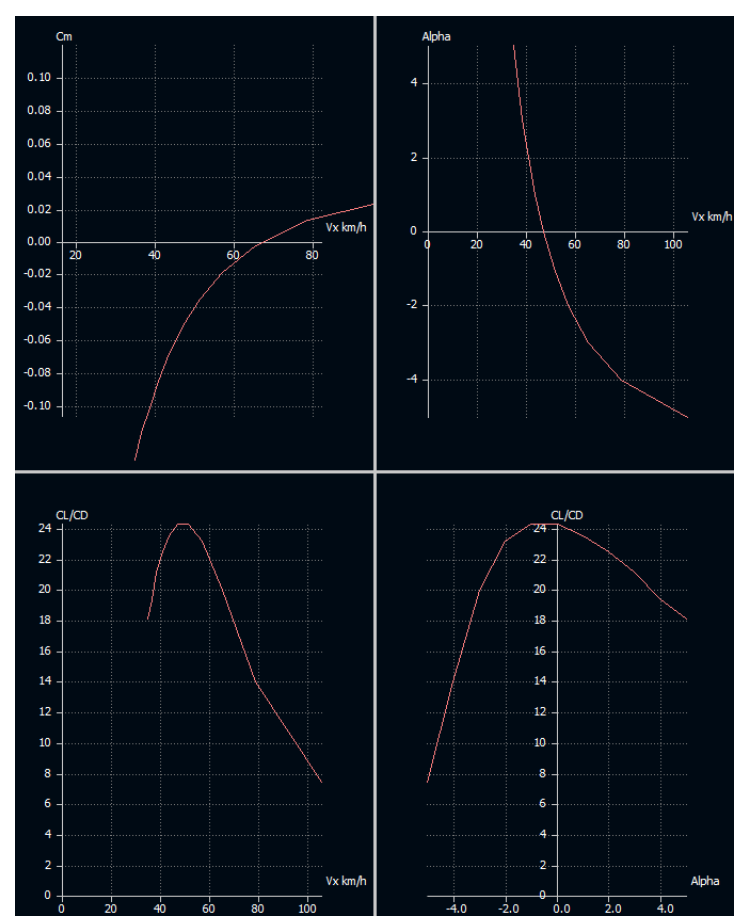

Fig. 14. Diagrams of flow over wing $W 2$ at the airspeed of $55 \mathrm{~km} / \mathrm{h}$. 
From the calculation it is seen that the moment of UAV stabilization $C m=0$ takes place at a speed $V=65 \mathrm{~km} / \mathrm{h}$; the angle of UAV attack becomes $\alpha=0^{\circ}$ at a speed $V=48 \mathrm{~km} / \mathrm{h}$; maximum lift-drag ratio $\mathrm{Cl} / \mathrm{Cd}$ is reached at a speed $V=50$ $\mathrm{km} / \mathrm{h}$; maximum lift-drag ratio $\mathrm{Cl} / \mathrm{Cd}$ occurs when $\alpha=0^{\circ}$.

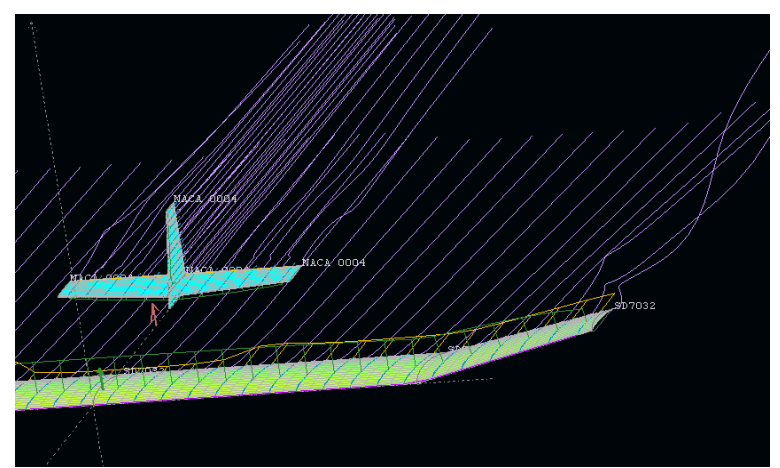

Fig. 15. The lift-drag ratio at $V=55 \mathrm{~km} / \mathrm{h}$ is $\mathrm{Cl} / \mathrm{Cd}=25 ; \mathrm{Cl}=0.5684$; $\mathrm{Cd}=$ 0.0225 .

\section{CONCLUSIONS}

From Table III and Figure 16 it is seen that such parameters as minimum drag from velocity, wing power factor from velocity, minimum vertical speed from glide speed, and coming moment of UAV stabilization from the speed by wing $W 2$ have lower values in terms of airspeed than wing $W 1$. This makes it possible to conclude that wing $W 2$ will be more efficient at the design cruising speed of $55 \mathrm{~km} / \mathrm{h}$ [12].

TABLE III

COMPARATIVE CHARACTERISTICS OF WINGS W 1 AND W 2

\begin{tabular}{|c|c|c|c|}
\hline \multicolumn{2}{|l|}{$W 1$} & \multicolumn{2}{|l|}{$W 2$} \\
\hline $\begin{array}{l}\mathrm{Cl} / \mathrm{Cd} \text { when } \\
\mathrm{V}=55 \mathrm{~km} / \mathrm{h}\end{array}$ & 25 & $\begin{array}{l}\mathrm{Cl} / \mathrm{Cd} \text { when } \\
\mathrm{V}=55 \mathrm{~km} / \mathrm{h}\end{array}$ & 25 \\
\hline $\mathrm{Cd}$ from $\mathrm{V}$ & 87 & $\mathrm{Cd}$ from $\mathrm{V}$ & 65 \\
\hline $\mathrm{Cd} / \mathrm{Cd}$ from $\mathrm{V}$ & $53 \mathrm{~km} / \mathrm{h}$ & $\mathrm{Cd} / \mathrm{Cd}$ from $\mathrm{V}$ & $50 \mathrm{~km} / \mathrm{h}$ \\
\hline $\mathrm{Cl}^{\wedge}(3 / 2) / \mathrm{Cd}$ from $\mathrm{V}$ & $58 \mathrm{~km} / \mathrm{h}$ & $\mathrm{Cl}^{\wedge}(3 / 2) / \mathrm{Cd}$ from $\mathrm{V}$ & $40 \mathrm{~km} / \mathrm{h}$ \\
\hline Vz from $V x$ & $45 \mathrm{~km} / \mathrm{h}$ & $\mathrm{Vz}$ from $\mathrm{Vx}$ & $39 \mathrm{~km} / \mathrm{h}$ \\
\hline $\mathrm{Cm}=0$ from $\mathrm{V}$ & $70 \mathrm{~km} / \mathrm{h}$ & $\mathrm{Cm}=0$ from $\mathrm{V}$ & $65 \mathrm{~km} / \mathrm{h}$ \\
\hline
\end{tabular}

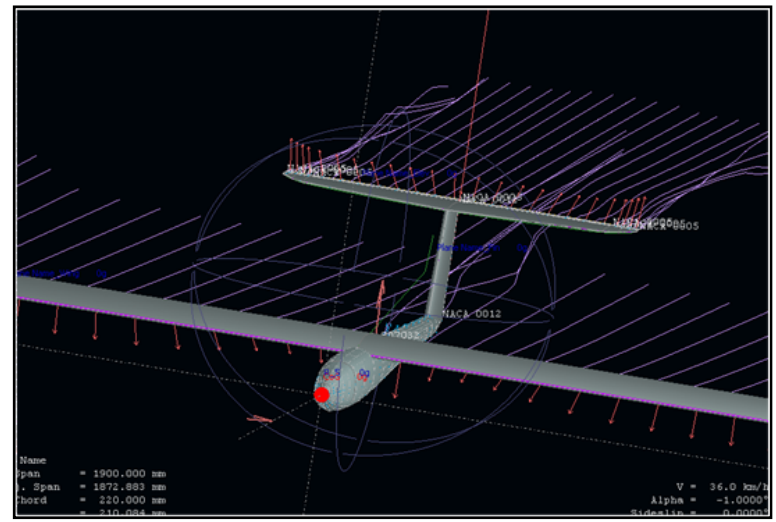

Fig. 16. Calculation of UAV prototype aerodynamics.
The calculation of power unit performance (Fig. 17) has shown that the flight time of the UAV prototype with increased takeoff weight is approximately 110 minutes, which fully corresponds to the set-up modernization parameter and even exceeds it [13].

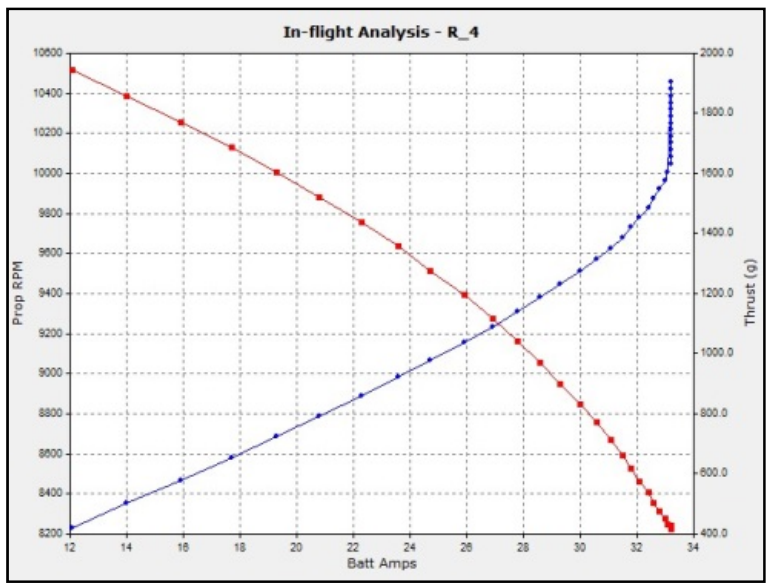

Fig. 17. In-flight analysis.

Flight predictions:

- $\quad$ stall speed $(\mathrm{m} / \mathrm{s})-10.1$

- optimal flight speed $(\mathrm{m} / \mathrm{s})-12.8$;

- throttle for optimal $(\%)-69$;

- flight time (m:s) - 110:14;

- motor temp at optimal $\left({ }^{\circ} \mathrm{C}\right)-37$;

- hands-off speed $(\mathrm{m} / \mathrm{s})-14.6$;

- throttle for hands-off $(\%)-77$;

- duration hands-off (m:s) - 105:30;

- motor temp hands-off $\left({ }^{\circ} \mathrm{C}\right)-39$;

- best rate of climb $(\mathrm{m} / \mathrm{s})-4.00$;

- rate of $\sin \mathrm{k}(\mathrm{m} / \mathrm{s})--0.87$.

According to theoretical calculations, the UAV prototype has undergone modernization, which includes manufacturing of new lifting surfaces (designed on the basis of theoretical calculations) and installation of a new power unit [14], [15]. The modernized UAV passed flight tests (Fig. 18) and demonstrated full compliance with the improved designed performance characteristics.

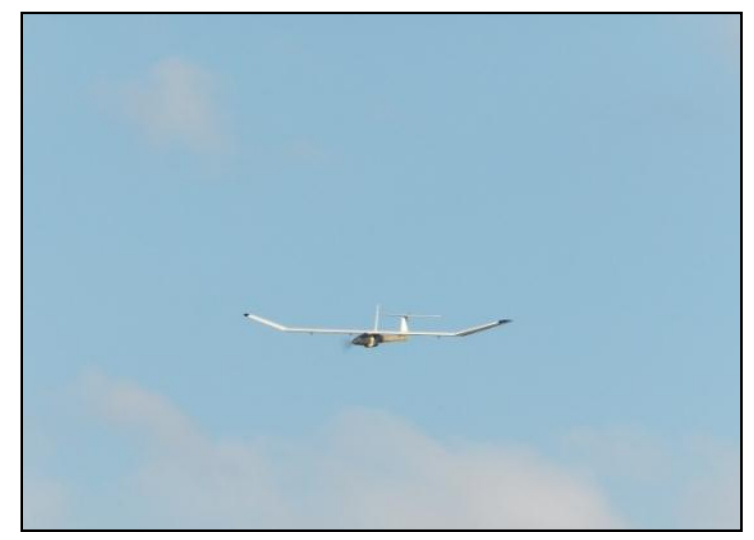

Fig. 18. Modernized UAV prototype in flight. 
Notations used in the calculations:

- alpha $\alpha$ - angle of attack;

- lift coef - lift coefficient;

- viscous drag coef - pressure drag;

- induced drag coef - induced drag;

- total drag coef - drag (is equal to viscous drag coef + inducted drag coef);

- total pitching moment coef - total pitching moment in relation to the centre of gravity;

- total rolling moment coef - total rolling moment in relation to the centre of gravity;

- glide ratio $\mathrm{Cl} / \mathrm{Cd}$;

- wing ratio $(C y / C x)$;

- power factor $C l^{\wedge}(3 / 2) / C d$ - wing power factor;

- lift - lift force in newtons;

- drag - drag in newtons;

- $V x$ - velocity along axis $x$;

- $\quad V z$ - velocity along axis $z$;

- descent angle atan $(\mathrm{Cd} / \mathrm{Cl})$ - angle of glide;

- pitching moment - wing pitching moment in relation to the centre of gravity.

\section{ACKNOWLEDGEMENTS}

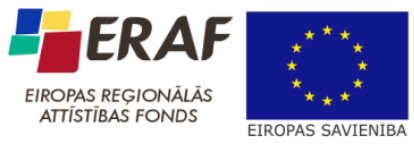

IEGULDĪJUMS TAVĀ NĀKOTNĒ

The research has been supported by the European Regional Development Fund within the framework of project "Development of an Unmanned Aircraft System and Creation of the Industrial Prototypes of Unmanned Aerial Vehicles for Performing the Tasks of Latvian National Economy". No.2010/0256/2DP/2.1.1.1.0/10/APIA/VIAA/070.

\section{REFERENCES}

[1] E. L. Bedrzhicky, B. S. Dubov and A. N. Radcig, Theory and Practice of Aerodynamic Experiments. Moscow: MAI, 1990.

[2] A. Urbahs, V. Petrovs, A. Jakovlevs and V. Bulanovs, Specificity of constructions and perspective of use and operations in transport systems UAS micro class: Proceedings of the International Conference Transport Means, October 21-22, pp. 202-206, Kaunas, Lietuva, 2011.

[3] A. Urbahs, M. Urbaha, V. Petrovs and A. Jakovlevs, Methods and means of the computer-aided design of unmanned aerial vehicle model: Proceeding of 2009 International Conference on Intelligent Engineering Systems (INES), pp. 211-213, Barbadosa, Barbados, 2009. http://dx.doi.org/10.1109/INES.2009.4924764

[4] A.Urbahs, K. Savkovs, V. Bulanovs, V. Petrovs and A. Jakovlevs, Multipurpose unmanned aerial vehicle design: Proceedings of the International Conference Transport Means, October 23-24, pp. 30-32, Kaunas, Lietuva, 2008.

[5] R. von Mises, Theory of Flight, Dover Publications, 1959.

[6] J. U. Shin, D. Kim and H. Myung, Micro aerial vehicle type wallclimbing robot mechanism: IEEE International Workshop on Robot and Human Interactive Communication Proceedings, August 26-29, pp. 722725, Gyeongju, China, 2013.

[7] F. S. Goncalves, J. P. Bodanese, R. Donadel, G. V. Raffo, J. E. NormeyRico and L. B. Becker, Small scale UAV with birotor configuration: International Conference on Unmanned Aircraft Systems, ICUAS 2013, May 28-31, pp. 761-768, Atlanta, USA, 2013.

[8] B. Shome and M. Radle, "Assessment of Transitional Model for Prediction of Aerodynamic Performance of Airfoils at Low Reynolds Number Flow Regime." SAE Technical Paper 2013-01-2314. Sep. 17, 2013. [Online]. Available: http://papers.sae.org/ [Accessed 20.01.2014].
[9] Y. X. Wu and M. Jiao, "Unmanned aerial vehicles take off from inclined surfaces in disaster situations." Nov. 2013. [Online]. Available: http://www.scientific.net/ [Accessed Jan. 21, 2013].

[10] S. Ricci, M. Castellani and G. Romanelli, "Multi-fidelity design of aeroelastic wing tip device," Journal of Aerospace Engineering, vol.227, pp. 1596-1604, 2013.

[11] S. G. Kontogiannis and J. A. Ekaterinaris, "Design, performance evaluation and optimization of a UAV", Aerospace Science and Technology, vol. 29 (1), pp. 339-350, 2013. http://dx.doi.org/10.1016/j.ast.2013.04.005

[12] G. S. C. Avellar, G. D. Thums, R. R. Lima, P. Iscold, L. A. B. Torres, and G. A. S. Pereira, On the development of a small hand-held multi-UAV platform for surveillance and monitoring: International Conference on Unmanned Aircraft Systems, ICUAS 2013, May 28-31, pp. 405-412, Atlanta, USA, 2013.

[13] Valyou, A. Ceruti, J. Miller, B. Pawlowski, P. Marzocca, M. Tranchitella, "Design, optimization, performances and flight operation of an all composite unmanned aerial vehicle". SAE Technical Paper 2013-012192. Sep. 17, 2013. [Online]. Available: http://papers.sae.org/ [Accessed 20.01.2014].

[14] K. Phungy and P. Morinz, "Modelling and energy evaluation of small convertible UAV." [Online]. Available: http://hal.upmc.fr/ [Accessed 20.01.2014].

[15] T. Singhanart, C. Srimontok, N. Pisitpan, S. Chitimaworaphan and W. Mongkhonchaiwiwat, "Design and analysis of UAV fuselage." Nov. 2012. [Online]. Available: http://www.scientific.net/ [Accessed Jan. 21, 2013].

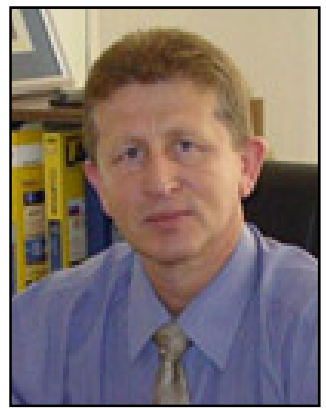

Aleksandrs Urbahs graduated from the Faculty of Mechanical Engineering, Riga Civil Aviation Engineering Institute in 1981. In 1986 he was awarded the Dr.sc.ing. degree by the same faculty. In 1997 he was awarded the Dr.habil.sc.ing. degree by Riga Aviation University. In the period of 1989-1999 - Vice Dean and Dean of the Faculty of Mechanical Engineering, Riga Aviation University. Since 1999 - Full-time Professor at Riga Technical University. In the period of 1999-2012 - Head of the Institute of Transport Vehicle Technologies at Riga Technical University. Since 2012 - Head of the Institute of Aeronautics at Riga Technical University. He holds 19 patents and has published 297 scientific papers.

His fields of research: aeronautics, nanomaterials, non-destructive methods of control, structural materials, unmanned vehicles, transport systems and logistics.

Address: Institute of Aeronautics, Faculty of Transport and Mechanical Engineering, Riga Technical University, Lomonosova 1A, k-1, Riga, LV1019, Latvia.

Phone: +371 67089990

E-mail: Aleksandrs.Urbahs@rtu.lv

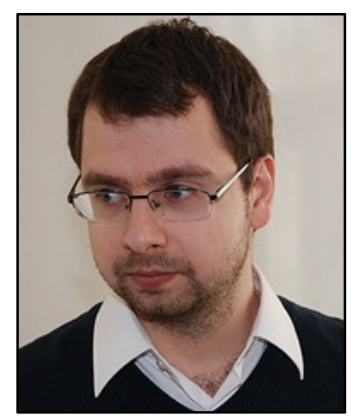

Vladimirs Petrovs received a degree of Master of Engineering Sciences from the Institute of Transport Vehicle Technologies, Faculty of Transport and Mechanical Engineering, Riga Technical University in 2009. In 2007 he received a Bachelor's Degree in Transport and Business Logistics from the Transport and Telecommunication Institute.

Work experience: Researcher at RTU, Institute of Aeronautics; Flight Operations Officer at LatCharter Airlines; SmartLynx Airlines, Flight Operations Department, ETOPS training, Crew Resource Management (CRM); Chief Designer of Unmanned Aerial Systems, Riga, Latvia.

Memberships in professional societies: Aircraft Owners and Pilot Association, AOPA; Air Safety Institute, a Division of the AOPA Foundation.

His fields of research: aeronautics, unmanned vehicles.

Address: Institute of Aeronautics, Faculty of Transport and Mechanical Engineering, Riga Technical University, Lomonosova 1A, k-1, Riga, LV1019, Latvia.

Phone: +37167089990

E-mail: Vladimirs.Petrovs@rtu.lv 


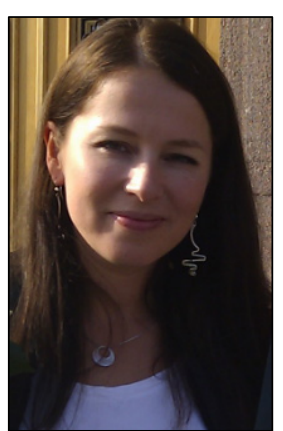

Margarita Urbaha graduated from the Faculty of Transport and Mechanical Engineering, Riga Technical University in 2011 and received the Dr.sc.ing. degree. Since 2012 she has been a Senior Researcher at the Institute of Aeronautics, Riga Technical University, and an Associate Professor at the Faculty of Transport and Mechanical Engineering, Riga Technical University. From 2010 to 2012 she was a Researcher at the Faculty of Transport and Mechanical Engineering, Riga Technical University. Since 2005 she has been a Project Manager at the Faculty of Transport and Mechanical Engineering, Riga Technical University. She is the author of 51 publications, 39

conference presentations

Her fields of research: aeronautics, unmanned vehicles, nano-composite coatings, non-destructive methods of control, transport systems and logistics.

Address: Institute of Aeronautics, Faculty of Transport and Mechanical Engineering, Riga Technical University, Lomonosova 1A, k-1, Riga, LV1019, Latvia.

Phone: +371 67089990. E-mail: Margarita.Urbaha@rtu.lv

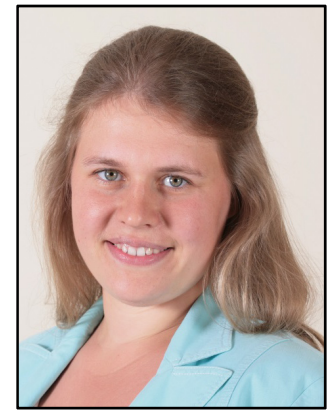

Kristine Carjova has been a Doctoral Student at the Institute of Aeronautics, Riga Technical University since 2011. In 2010 she obtained a degree of Master of Science at the Latvian Maritime Academy. She graduated from the Latvian Maritime Academy and obtained a Specialisation of Engineer-Ship Navigator. Work experience: 2004-2007 - Navigator of Merchant Vessel. 2009-2011 - Captain on ASD tugboat at JSC PKL Flote. Since August 2011 - Researcher at the Institute of Aeronautics, Riga Technical University.

Her fields of research: aeronautics, nanomaterials, non-destructive methods of control, structural materials, unmanned vehicles, transport systems and logistics.

Address: Institute of Aeronautics, Faculty of Transport and Mechanical Engineering, Riga Technical University, Lomonosova 1A, k-1, Riga, LV1019, Latvia.

Phone: +371 67089990

E-mail: $\underline{\text { Kristine.Carjova@rtu.lv }}$ 